\title{
Chiari I malformation, delayed gross motor skills, severe speech delay, and epileptiform discharges in a child with FOXP1 haploinsufficiency
}

\author{
Christopher W Carr ${ }^{1,4}$, Daniel Moreno-De-Luca ${ }^{2,4}$, Colette Parker ${ }^{1}$, Holly H Zimmerman ${ }^{1}$, Nikki Ledbetter ${ }^{2}$, \\ Christa Lese Martin ${ }^{2}$, William B Dobyns ${ }^{3}$ and Omar A Abdul-Rahman ${ }^{\star, 1}$
}

Human FOXP2 deficiency has been identified as a cause of hereditary developmental verbal dyspraxia. Another member of the same gene family, FOXP1, has expression patterns that overlap with FOXP2 in some areas of the brain, and FOXP1 and FOXP2 have the ability to form heterodimers. These findings suggest the possibility that FOXP1 may also contribute to proper speech development. However, no such role of FOXP1 has been established to date. Recently, a child was reported who presented with a 3p13-14.1 deletion of four genes, including FOXP1, and a constellation of deficits that included speech delay. In this study, we report the case of a patient with a single deletion of FOXP1. This patient presented with speech and motor developmental delays, a Chiari I malformation, and epileptiform discharges. The nature of the speech deficit is different from the primary oromotor verbal dyspraxia found in patients with FOXP2 deficiency. The patient's developmental deficits may support a role for FOXP1 in the development of verbal and motor skills.

European Journal of Human Genetics (2010) 18, 1216-1220; doi:10.1038/ejhg.2010.96; published online 23 June 2010

Keywords: developmental delay; deletion; FOXP; speech deficit; Chiari I malformation

\section{INTRODUCTION}

FOXP1, located on 3p14.1, is a member of the FOX gene family of winged-helix/forkhead DNA-binding proteins. ${ }^{1}$ To date, the association of FOXP1 with human pathology has been confined to B-cell development and lymphomas. ${ }^{2}$ In comparison, more is known about the role of Foxp1 in murine pathology. In the last decade, Foxp1 deficiency has been associated with defective lymphopoiesis ${ }^{3}$ and cardiac development. ${ }^{4}$ Murine models have also uncovered the role of Foxp1 as an accessory factor of Hox transcription factors that regulate the projection and connection of motor neurons to target muscles. ${ }^{5,6}$ The absence of Foxp1 causes disordered, random connection of motor neurons to muscles. ${ }^{7,8}$

FOXP2 belongs to the same family of genes as FOXP1. FOXP2 haploinsufficiency has been implicated in the etiology of a familial verbal dyspraxia (ie, impairments in learning and producing sequences of mouth movements involved in fluent speech). This discovery began with the characterization of a three-generation family who had deficits in orofacial praxis, expressive language, receptive vocabulary and grammar, and nonverbal coding skills. ${ }^{9-11}$ Subsequently, an unrelated individual with a similar dyspraxia was identified, and molecular studies revealed disruptions in the FOXP2 gene of all affected individuals. ${ }^{12}$ Since then, additional cases of verbal dyspraxia caused by FOXP2 mutations and chromosomal rearrangements have been reported. ${ }^{13-16}$ Recent FOXP2 studies have focused on the identification of cerebral structures influenced by the FOXP2 transcription factor, ${ }^{17,18}$ and multiple transcriptional targets in the human basal ganglia and inferior frontal cortex have been identified. ${ }^{19,20}$

The association of human FOXP2 with speech deficits is mirrored in animal models. Similar to humans, songbirds possess the ability to modify innate vocalizations. Haesler et a ${ }^{21}$ found that the knockdown of FoxP2 in the basal ganglia of zebra finches resulted in incomplete and inaccurate vocal imitation, a finding that likely parallels the verbal dyspraxia seen in FOXP2-haploinsufficient humans. Interestingly, in zebra finches and humans, FoxP1 and FoxP2 have some overlapping expression in subcortical structures that contribute to the coordination of movement, including those needed for complex vocalization. ${ }^{22}$ With this colocalization of FoxP1 and FoxP2 expression in some regions of the brain, Teramitsu et $a^{22}$ hypothesized that these genes function together to regulate the development of neurological structures required for fluent vocal control. Furthermore, Foxp1 and Foxp2 can interact with one another, forming heterodimers. ${ }^{23}$ This ability to interact lends support to the hypothesis that both FOXP1 and FOXP2 may collaborate in a common pathway that influences the proper formation and function of circuits used in learned articulation.

Although FOXP2 has been formally associated with deficits in verbal expression, the role of FOXP1 deficiency in speech deficits remains to be established. In 2009, Vernes et al ${ }^{24}$ analyzed FOXP1 in 49 patients with developmental verbal dyspraxia (DVD). A nonsynonymous coding change was discovered in only one patient, and, although the same mutation was present in a control sample, the possibility that the mutation contributed to the patient's DVD could

${ }^{1}$ Department of Pediatrics, University of Mississippi Medical Center, Jackson, MS, USA; ${ }^{2}$ Department of Human Genetics, Emory University, Atlanta, GA, USA; ${ }^{3}$ Department of Human Genetics, University of Chicago, Chicago, IL, USA

*Correspondence: Dr O Abdul-Rahman, Department of Pediatrics, University of Mississippi Medical Center, 2500 North State Street, Jackson, MS 39216, USA. Tel: +6019841940; Fax: +6019841916; E-mail: oabdulrahman@umc.edu

${ }^{4}$ These two authors contributed equally to this work.

Received 3 August 2009; revised 14 May 2010; accepted 18 May 2010; published online 23 June 2010 
not be ruled out. Although finding that FOXP1 mutations were not likely a major cause of DVD, Vernes et al ${ }^{24}$ did posit that FOXP1 remains a candidate for involvement in neurodevelopmental disease. A recent case report described a patient with speech delay, contractures, blepharophimosis, hypertonia, and a deletion of four genes in 3p13-14.1, including FOXP1. ${ }^{25}$ This case is consistent with the hypothesis of a potential role of FOXP1 in speech development. In this study, we report a patient with a deletion involving only the FOXP1 gene whose deficits support a role of FOXP1 in human motor and speech development.

\section{CLINICAL REPORT}

The proband, a male born at 37 weeks of gestation, is the second child of a 32-year-old Caucasian mother and a 33-year-old Caucasian father. The prenatal course was unremarkable. After delivery, the infant had a 'puffy' left face, but otherwise appeared normal. Growth parameters were normal.

Subsequently, gross motor skills were delayed; the patient did not walk until 16 months of age. A neurological evaluation at 26 months was undertaken because of speech delays. An MRI revealed a normal gyral pattern, a dysmorphic but intact corpus callosum, mild hypoplasia of the cerebellar vermis, and a Chiari I malformation (herniation of the cerebellar tonsils through the foramen magnum) (Figure 1). At 30 months, the patient underwent suboccipital decompression of the malformation, with some improvement in motor development thereafter.

At 41 months, the patient was found to be imitating sounds and attempting words. The patient had difficulty articulating entire words, and was only able to verbalize one or two syllables of multisyllabic words. Most often, he could verbalize vowels but not consonants. For example, an attempt to repeat the word 'dad' yielded only the short 'a' sound. The patient exhibited no deficits of oromotor coordination that could explain this deficit, as he had no feeding difficulty, was able to suck through a straw, and did not dribble excessively. The patient compensated for his speech deficit using rudimentary sign language, using $\sim 25$ signs with some phrase formation. Given the patient's effective use of sign language, the patient's speech deficit appears to

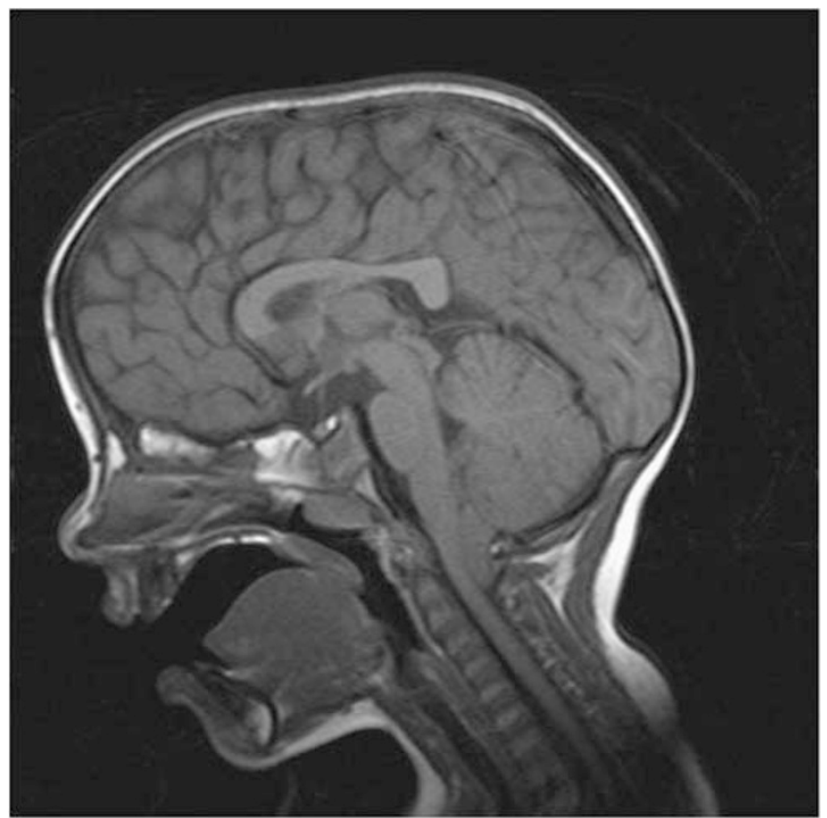

Figure 1 MRI showing the patient's Chiari I malformation. be a problem of verbal expression and not a failure of language development. No formal language, intelligence, nor praxis testing was made available for this patient.

Physical examination at 41 months demonstrated a height of $100 \mathrm{~cm}$ (10th centile), weight of $15.6 \mathrm{~kg}\left(10^{\text {th }}-25 \mathrm{th}\right.$ centile), and head circumference of $52 \mathrm{~cm}\left(50^{\text {th }}-75\right.$ th centile). Dysmorphic features were noted as indicated in Figure 2. The neurological examination showed intact cranial nerves except for mild ptosis and mildly decreased facial expression. There was decreased tone axially and a slightly increased tone of the extremities. Reflexes were slightly increased as well. The patient developed staring spells with motor arrest at the age of 4 years. An electroencephalogram noted epileptiform discharges in the left frontocentral region and the right posterior region. Oxcarbazepine was initiated.

A review of the patient's family history revealed that several of the proband's relatives, including his mother, suffered from a mild sensorineural hearing loss of unknown etiology. In addition, the proband's maternal uncle has an auditory processing problem (no further detail about this deficit is available). No hearing difficulty has been detected in the patient. The mother has normal speech and language abilities, so no deficiencies in her communication skills have been contributing to the patient's developmental deficits.

An echocardiogram and renal ultrasound were normal. Chromosome analysis showed a normal 46,XY karyotype at a band resolution of 600. Cytogenetic array analysis followed with notable results discussed below.

\section{MOLECULAR CYTOGENETIC ANALYSIS}

Whole-genome cytogenetic array comparative genomic hybridization (aCGH) analysis was carried out using a custom-designed $44 \mathrm{~K}$ oligonucleotide array with a backbone resolution of $\sim 250 \mathrm{~kb}^{26} \mathrm{An}$ $\sim 1.0 \mathrm{Mb}$ interstitial deletion of 3 p14.1 was identified that only involved the FOXP1 gene (Figure 3) ${ }^{27}$; FISH analysis confirmed the deletion. No other copy-number abnormalities were found on the $44 \mathrm{~K}$

a

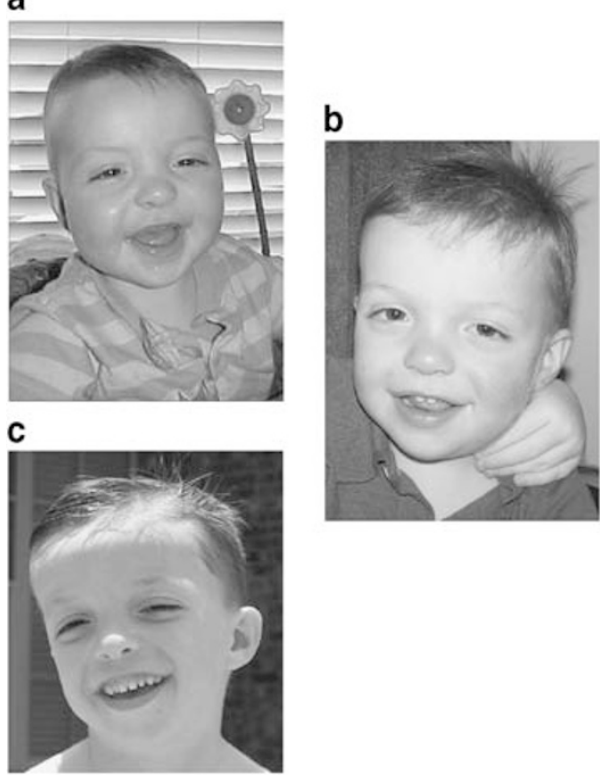

Figure 2 The patient's dysmorphology includes a broad forehead, orbital hypertelorism, down-slanting palpebral fissures, bilateral ptosis, short nose, broad nasal tip, smooth philtrum, and slightly down-turned corners of the mouth. Facial photos demonstrate the evolution of the facial phenotype from (a) 10 months to (b) 20 months to (c) 46 months. 

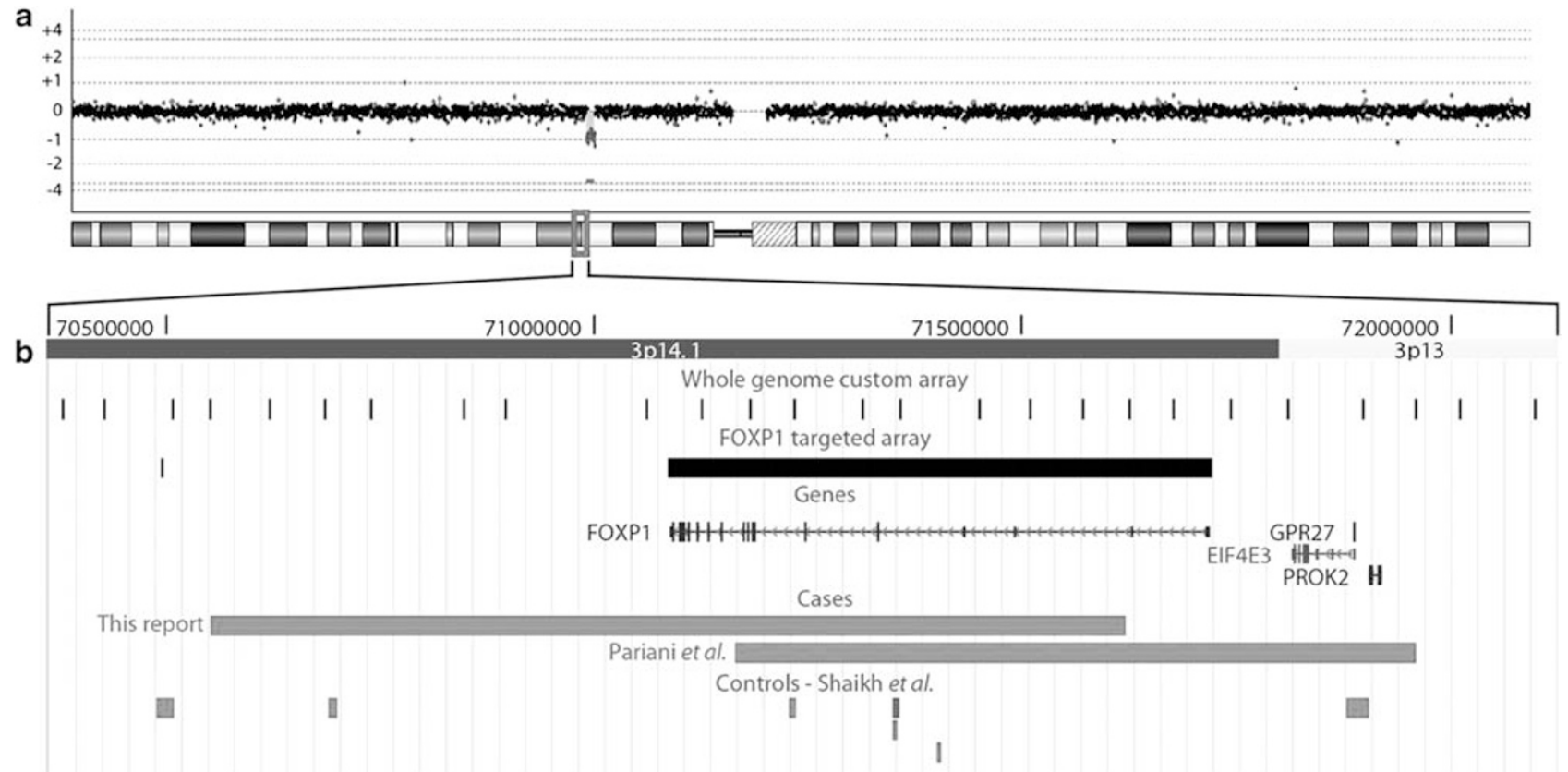

Figure 3 The deletion of FOXP1 at 3p14.1. (a) Array results for the proband are shown above the ideogram of chromosome 3. Each dot is an oligonucleotide probe; those with normal copy number have a log2 ratio of $\sim 0$, whereas those in the deleted region have a log2 of less than -0.32 . The deleted region is boxed. (b) UCSC Genome Browser view of the FOXP1 deletion. The deletion described in this report and a similar larger deletion from a previous study 25 are shown as red bars. Probes on the whole-genome array and FOXP1-targeted array appear as black vertical lines. Deletions (red bars) and duplications (green bars) found in apparently normal control individuals from a previous study27 are also displayed. The minimal deleted region is chr3:7054992371618670; the maximum deleted region is chr3:70508118-71618932. The color reproduction of this figure is available on the html full text version of the manuscript.

oligonucleotide array. High-resolution aCGH was performed for fine mapping using a custom-designed FOXP1-targeted array with one exonic probe every $15 \mathrm{bp}$ and one intronic probe every $500 \mathrm{bp}$. These analyses refined the minimal deleted region to chr3:7054992371618670 (hg18). Parental FISH analyses demonstrated that the deletion is de novo.

\section{DISCUSSION}

Although only FOXP2 has been associated with neurodevelopmental deficits in humans to date, the patient reported here suggests that FOXP1 deficiency may cause motor and speech deficits. Similar to the patient reported herein, patients with FOXP2 haploinsufficiency have normal gross oromotor function (eg, no feeding difficulties, no excessive dribbling). However, this patient's speech deficit is fundamentally different from that seen in FOXP2 deficiency. This patient has limited verbal output, has greater difficulty verbalizing consonants than vowels, and has difficulty in producing multisyllabic speech. In contrast, patients with FOXP2 haploinsufficiency have greater verbal output, and these patients' ability to verbalize consonants and vowels is the same. These patients do not have the same difficulty in producing multisyllabic speech as the patient reported herein. FOXP2-haploinsufficient patients' deficit lies in the coordination of rapid sequences of articulatory gestures; their verbalizations contain more errors as the length and/or complexity of utterances increases. ${ }^{11}$ Another significant difference between the FOXP2-deficient phenotype and our patient is gross motor skill. The patient reported herein has experienced delays in gross motor skill acquisition. FOXP2haploinsufficient patients feature normal gross motor development.

A previous case report by Pariani et al ${ }^{25}$ described a patient with a deletion of four genes in 3p13-14.1, including FOXP1. This patient's constellation of pathology included speech delay, gross motor skill delay, hypertonia, contractures, and blepharophimosis. Table 1 offers a comparison of key features of Pariani's patient and the patient reported herein. Some similarities between these two FOXP1-deficient patients exist, but, on balance, the phenotypic differences are greater. Both patients experienced speech delay; at 23 months of age, Pariani's patient was producing vowel sounds but not words. In addition, both patients also experienced delays in gross motor skill acquisition, although the degree of severity is worse in Pariani's patient. This latter patient only began cruising at the age of 18 months, whereas our patient began walking at 16 months. Contractures present in Pariani's patient were absent in our patient. Hypertonia was a key finding in Pariani's patient, whereas our patient only exhibited slightly increased extremity muscle tone. The nature of facial dysmorphology also differs between the two patients. These disparate findings suggest that the previously reported patient's phenotype was influenced by the deletion of not just FOXP1 but also EIF4E3, PROK2, and GPR27. Alternatively, these phenotypic differences could be due to a highly variable expressivity of FOXP1 haploinsufficiency.

In the current patient, FOXP1 is the only deleted gene, and rearrangements involving FOXP1 are absent from the Database of Genomic Variants. ${ }^{28,29}$ Therefore, FOXP1 is a likely etiological basis of the patient's constellation of developmental deficits. However, Chiari I malformations can adversely affect sensory and motor development, and so the possibility exists that the patient's symptoms may have been exacerbated or even caused by his Chiari I malformation. Possibly, the surgical treatment of the patient's Chiari I malformation, combined with the dynamic plasticity of the young central nervous system, may explain the patient's relatively late improvement in motor function, as has been reported in other cases. ${ }^{30}$ Alternatively, the patient's late improvement in motor function may suggest that the impact of FOXP1 on human motor neuron development is modified 
Table 1 A comparison of the phenotypes of two patients with FOXP1 deletions

\begin{tabular}{|c|c|c|}
\hline & Pariani et $\mathrm{al}^{25}$ & Current report \\
\hline Deleted genes & FOXP1, EIF4E3, PROK2, GPR27 & FOXP1 \\
\hline \multicolumn{3}{|l|}{ Development } \\
\hline Speech delay & Producing vowel sounds, but no words at 23 months & $\begin{array}{l}\text { Producing almost exclusively vowel sounds, but no words at } \\
\text { the age of } 41 \text { months }\end{array}$ \\
\hline Gross motor skill delay & $\begin{array}{l}\text { Sat upright unassisted at } 15 \text { months } \\
\text { Cruising at } 18 \text { months }\end{array}$ & Walking at 16 months \\
\hline \multicolumn{3}{|l|}{ Neurological features } \\
\hline Muscle tone & Hypertonia & $\begin{array}{l}\text { Slightly increased extremity tone } \\
\text { Decreased axial tone }\end{array}$ \\
\hline Reflexes & Normal & Slightly increased \\
\hline Other & Intermittent daily muscle spasms since birth & $\begin{array}{l}\text { Staring spells with motor arrest } \\
\text { Mild ptosis }\end{array}$ \\
\hline Facial dysmorphology & $\begin{array}{l}\text { Upturned alae nasi } \\
\text { Blepharophimosis } \\
\text { Epicanthal folds } \\
\text { Prominent cheeks }\end{array}$ & $\begin{array}{l}\text { Alae nasi unremarkable } \\
\text { Broad forehead } \\
\text { Hypertelorism } \\
\text { Down-slanting palpebral fissures } \\
\text { Smooth philtrum } \\
\text { Slightly down-turned corners of mouth }\end{array}$ \\
\hline Musculoskeletal & $\begin{array}{l}\text { Contractures } \\
\text { Persistent flexion of phalanges }\end{array}$ & $\begin{array}{l}\text { No contractures } \\
\text { Normal positioning of phalanges }\end{array}$ \\
\hline Genitalia & Bilateral cryptorchidism & Descended testes bilaterally \\
\hline Hands & Bilateral single transverse palmar crease & $\begin{array}{l}\text { Bridged palmar creases } \\
\text { Persistent fetal pads }\end{array}$ \\
\hline MRI & $\begin{array}{l}\text { Mild asymmetric enlargement of ventricles } \\
\text { and sulci, consistent with minor atrophy }\end{array}$ & $\begin{array}{l}\text { Dysmorphic but intact corpus callosum } \\
\text { Mild hypoplasia of the cerebellar vermis } \\
\text { Chiari I malformation }\end{array}$ \\
\hline
\end{tabular}

by other factors not found in animal models. Indeed, attribution of the patient's full complement of deficits to the Chiari I malformation would be difficult. Previous studies have identified an association between Chiari I malformations and speech delays, ${ }^{31-33}$ suggesting that these abnormalities may be clustering together in some instances and might have a common pathogenetic background. Our report may support this association, identifying FOXP1 haploinsufficiency as one possible origin for this particular phenotype. At the least, the Chiari malformation is an important confounder that complicates the interpretation of the effect of FOXP1 deficiency on the patient's speech and motor development.

The patient reported herein developed seizures after decompression of his Chiari malformation. Although cerebellar fits have been demonstrated in children with Chiari malformation, epilepsy is thought to be rare. ${ }^{34}$ However, one case series suggests that some patients with Chiari I malformation may have cerebral microdysgenesis as evidenced by single-photon emission computed tomography. ${ }^{35}$ FOXP1 haploinsufficiency may also contribute to aberrations in cerebral-cerebellar networking, resulting in seizure activity, although this hypothesis requires investigation.

Even with the Chiari I confounder, the concurrence of a FOXP1 deletion and the patient's constellation of deficits is compelling enough to merit genetic studies of persons with gross motor developmental delay and/or verbal deficits. With respect to the latter, the identification of only one FOXP1 mutation among 49 patients with DVD and the inability to assign causality to this single mutation suggest that larger sample sizes may be needed to identify FOXP1 mutations, especially if such mutations have a frequency less than
FOXP2 gene anomalies, in which $\sim 2 \%$ of patients carry a deleterious genetic change. ${ }^{24}$

\section{CONFLICT OF INTEREST}

The authors declare no conflict of interest.

\section{ACKNOWLEDGEMENTS}

We thank the patient's family for their participation.

1 Shu W, Yang H, Zhang L, Lu MM, Morrisey EE: Characterization of a new subfamily of winged-helix/forkhead (Fox) genes that are expressed in the lung and act as transcriptional repressors. J Biol Chem 2001; 276: 27488-27497.

2 Banham AH, Connors JM, Brown PJ et al: Expression of the FOXP1 transcription factor is strongly associated with inferior survival in patients with diffuse large B-cell lymphoma. Clin Cancer Res 2005; 11: 1065-1072.

$3 \mathrm{Hu} \mathrm{H}$, Wang B, Borde $\mathrm{M}$ et al: Foxp1 is an essential transcriptional regulator of B cell development. Nat Immunol 2006; 7: 819-826.

4 Wang B, Weindenfeld J, Lu MM et al: Foxp1 regulates cardiac outflow tract endocardial cushion morphogenesis and myocyte proliferation and maturation. Development 2004; 131: 4477-4487.

5 Dasen JS, Liu JP, Jessell TM: Motor neuron columnar fate imposed by sequential phases of Hox-c activity. Nature 2003; 425: 926-933.

6 Dasen JS, Tice BC, Brenner-Morton S, Jessell TM: A Hox regulatory network establishes motor neuron pool identity and target-muscle connectivity. Cell 2005; 123: 477-491.

7 Dasen JS, De Camilli A, Wang B, Tucker PW, Jessell TM: Hox repertoires for motor neuron diversity and connectivity gated by a single accessory factor, FoxP1. Cell 2008; 134: 304-316.

8 Rousso DL, Gaber ZB, Wellik D, Morrissey EE, Novitch BG: Coordinated actions of the forkhead protein Foxp1 and Hox proteins in the columnar organization of spinal motor neurons. Neuron 2008; 59: 226-240. 
9 Watkins KE, Dronkers NF, Vargha-Khadem F: Behavioral analysis of an inherited speech and language disorder: comparison with acquired aphasia. Brain 2002; 125: 452-464.

10 Hurst JA, Baraitser M, Auger E, Graham F, Norel SV: An extended family with a dominantly inherited speech disorder. Dev Med Child Neurol 1990; 32: 352-355.

11 Vargha-Khadem F, Watkins K, Alcock K, Fletcher P, Passingham R: Praxic and nonverbal cognitive deficits in a large family with a genetically transmitted speech and language disorder. Proc Natl Acad Sci USA 1995; 92: 930-933.

12 Lai CSL, Fisher SE, Hurst JA, Vargha-Khadem F, Monaco AP: A forkhead-domain gene is mutated in a severe speech and language disorder. Nature 2001; 413: 519-523.

13 MacDermot KD, Bonora E, Sykes $\mathrm{N}$ et al: Identification of FOXP2 truncation as a novel cause of developmental speech and language deficits. Am J Hum Genet 2005; 76: 1074-1080.

14 Feuk L, Kalervo A, Lipsanen-Nyman $M$ et al: Absence of a paternally inherited FOXP2 gene in developmental verbal dyspraxia. Am J Hum Genet 2006; 79 : 965-972.

15 Lennon PA, Cooper ML, Peiffer DA et al: Deletion of 7q31.1 supports involvement of FOXP2 in language impairment: clinical report and review. Am J Med Genet A 2007; 143: 791-798.

16 Shriberg LD, Ballard KJ, Tomblin JB, Duffy JR, Odell KH, Williams CA: Speech, prosody, and voice characteristics of a mother and daughter with a 7;13 translocation affecting FOXP2. J Speech Lang Hear Res 2006; 49: 500-525.

17 Lai CS, Gerrelli D, Monaco AP, Fisher SE, Copp AJ: FOXP2 expression during brain development coincides with adult sites of pathology in a severe speech and language disorder. Brain 2003; 126: 2455-2462.

18 Liégeois F, Baldeweg T, Connelly A, Gadian DG, Mishkin M, Vargha-Khadem F: Language fMRI abnormalities associated with FOXP2 gene mutation. Nat Neurosci 2003; 6: 1230-1237.

19 Spiteri E, Konopka G, Coppola G et al: Identification of the transcriptional targets of FOXP2, a gene linked to speech and language, in developing human brain. Am J Hum Genet 2007; 81: 1144-1157.

20 Vernes SC, Spiteri E, Nicod J: High-throughput analysis of promoter occupancy reveals direct neural targets of FOXP2, a gene mutated in speech and language disorders. Am J Hum Genet 2007; 81: 1232-1250.

21 Haesler S, Rochefort C, Georgi B, Licznerski P, Osten P, Scharff C: Incomplete and inaccurate vocal imitation after knockdown of FoxP2 in songbird basal ganglia nucleus Area X. PLoS Biol 2007; 5: 2885-2897.
22 Teramitsu I, Kudo LC, London SE, Geschwind DH, White SA: Parallel FoxP1 and FoxP2 expression in songbird and human brain predicts functional interaction. $J$ Neurosci 2004: 24: 3152-3163.

23 Li S, Weindenfeld J, Morrisey EE: Transcriptional and DNA binding activity of the Foxp 1/2/4 family is modulated by heterotypic and homotypic protein interactions. Mol Cell Biol 2004; 24: 809-822.

24 Vernes SC, Macdermot KD, Monaco AP, Fisher SE: Assessing the impact of FOXP1 mutations on developmental verbal dyspraxia. Eur J Hum Genet 2009; 17: 1354-1358.

25 Pariani MJ, Spencer A, Graham JM, Rimoin DL: A 785 kb deletion of 3p14.1p13, including the FOXP1 gene, associated with speech delay, contractures, hypertonia and blepharophimosis. Eur J Med Genet 2009; 52: 123-127.

26 Baldwin EL, Lee JY, Blake DM et al: Enhanced detection of clinically relevant genomic imbalances using a targeted plus whole genome oligonucleotide microarray. Genet Med 2008; 10: 415-429.

27 Shaikh TH, Gai X, Perin JC et al: High-resolution mapping and analysis of copy number variations in the human genome: a data resource for clinical and research applications. Genome Res 2009; 19: 1682-1690.

28 Lafrate AJ, Feuk L, Rivera MN et al: Detection of large-scale variation in the human genome. Nat Genet 2004; 36: 949-951.

29 Database of Genomic Variants http://projects.tcag.ca/variation. Accessed on 20 May 2009.

30 Ahmmed AU, Mackenzie I, Das VK, Chatterjee S, Ly RH: Audio-vestibular manifestations of Chiari malformation and outcome of surgical decompression: a case report. J Laryngol Otol 1996; 110: 1060-1064.

31 Grosso S, Scattolini R, Paolo G, DiBartolo RM, Morgese G, Balestri P: Association of Chiari I malformation, mental retardation, speech delay, and epilepsy: a specific disorder? Neurosurgery 2001; 49: 1099-1103; discussion 1103-1104.

32 de Vasconcelos Hage SR, Cendes F, Montenegro MA, Abramides DV, Guimarães CA, Guerreiro MM: Specific language impairment: linguistic and neurobiological aspects. Arq Neuropsiquiatr 2006; 64 (2A): 173-180.

33 Haapanen ML: CHERI: time to identify the syndrome? J Craniofac Surg 2007; 18: 369-373.

34 Pandey A, Robinson S, Cohen AR: Cerebellar fits in children with Chiari I malformation. Neurosurg Focus 2001; 11: E4.

35 Iannetti P, Spalice A, De Felice Ciccoli C, Bruni O, Festa A, Maini CL: Seizures in paediatric Chiari type I malformation: the role of single-photon emission computed tomography. Acta Paediatr 2002; 91: 313-317. 